\title{
Humans as Social Being and Part of Nature
}

\author{
Regine Kather*
}

\begin{abstract}
Humans are, as Cassirer has demonstrated, an animal symbolicum that interprets the world by means of signs. Since the second half of the $20^{\text {th }}$ century the relation of cultures is influenced strongly by modern technology: On the one hand, nearly every culture is longing for modern technology to achieve a more comfortable life; and, on the other, modern technology changes the way of life deeply. At first sight technology seems to be a neutral instrument, a mere tool that is compatible with every way of life and does not interfere into religious and ethical orientation. But it is definitely an expression of cultural values; it produces completely new wishes and hopes and undermines inevitably traditional forms of life - a process, which implies great dangers and opportunities. First, humans must reflect on their way of life consciously and decide autonomously between alternatives; secondly the growing social standard leads to the destruction of nature which is the basis of human life. Though living in different cultures, humans have the ethical obligation to preserve nature - for their own and nature's sake.
\end{abstract}

\section{The Variety of Human Culture}

The process of globalization that has been initiated by modern technology implies new ethical challenges. By phone, television and internet information spreads around the world within a few minutes; people and goods are moved by airplane within hours

* Professor, Faculty of Philosophy, Universität Freiburg, Germany. Email: regine.kather@philosophie.uni-freiburg.de. 
from one continent to another. Yet economical, technical and functional processes cannot raise the awareness of ethical values. Are values rooted only in cultural traditions and consent - or can humans discover at least a few guide values they share with each other? ${ }^{1}$

Let us first reflect on the foundation of culture: More than 50000 years ago humans started to create symbols by which they could express and communicate their thoughts and emotions, their needs and questions. ${ }^{2}$ Meaning is represented by a sensual medium, by colour, sound or physical objects. However humans do not express themselves by scattered and isolated symbols. They are combined by complex rules. The variation of these rules and of the fundamental categories, of time, space, substance, and causality, creates different symbolic forms: Myth and religion, language and art, science and technology are based on different perspectives on reality. While science and technology separate subject and object, they are intertwined in art, language, religion, and myth. Humans, as Cassirer argues, can be defined as 'animal symbolicum'. ${ }^{3}$

Every culture is based on the interplay of technology, myth, art, language, science and religion. All humans are embedded in culture as medium of their life; it is produced by an ongoing process of interpretation which connects all members of the human family in past and present. Though traditions and values vary, their anthropological foundation remains the same. At this point of

Cf. R. A. Mall, Philosophie im Vergleich der Kulturen. Interkulturelle Philosophie: Eine neue Orientierung, Darmstadt 1995. H. Kimmerle, Interkulturelle Philosophie: Eine Einführung, Hamburg 2002. H. R. Yousefi \& R. A. Mall, Grundpositionen der interkulturellen Philosophie, Nordhausen: 2005. C. Antweiler, Was ist den Menschen gemeinsam? Über Kultur und Kulturen, Darmstadt: 2007.

I.Tattersall, "Wir waren nicht die Einzigen" in Spektrum Dossier 3/2000: Die Evolution des Menschen, 46f.

3 Cf. E. Cassirer, Versuch über den Menschen. Einführung in eine Philosophie der Kultur, Frankfurt/M:1990. O. Schwemmer, Die kulturelle Existenz des Menschen, Berlin: 1997. 
argumentation cultural relativism seems to be inevitable: Every culture develops its own schemes of interpretation, its goals and values, and its modes of explanation.

But though the symbolic forms are based on interpretation and refer to the historical context, they are not mere construction as Nietzsche, postmodernism, and constructivism suppose. Survival does not only depend on mental acts, but on concrete actions. Cassirer, who has been strongly influenced by Kant and Goethe, was well-aware that the symbolic interpretation of reality has pragmatic implications. The symbolic schemes are clues to successful actions. If they fail, a new interpretation of reality is enforced. On the one hand these schemes determine how humans understand their surrounding and themselves; on the other hand they are modified by new challenges. The symbolic forms are not static; they develop in accordance with the challenges they respond to. To the point Cassirer compares the symbolic forms with the organs of an organism: ${ }^{4}$ They do not reveal how reality is in itself, but they select and transform the information they receive. Nevertheless their function depends on the input from the surrounding, to which they must be adapted. Organs mediate between the external and the inner world. Organs in their bodily and mental meaning open up reality, they are windows to the world, but they show the world under a specific form of interpretation. Symbolic forms are neither copies of an object nor based on habits. The observation is guided by an intentional act that has at least to a certain degree to correspond to the object perceived. The intention determines how the world is perceived mentally, emotionally, and sensually. If the symbolic interpretation of an event changes fundamentally, the relation of humans to it will also change. In comparison to a scientific interpretation of nature a mythological one implies therefore a completely different behaviour.

None of the symbolic forms can be replaced by or reduced to another one. The variety within every culture and the diversity of

4 E. Cassirer, Wesen und Wirkung des Symbolbegriffs, Darmstadt: 19948 ,7. 
cultures is based on the interplay of symbolic forms that varies in different ages and cultures. ${ }^{5}$ Western culture for example is at present dominated by a scientific and technical worldview, while the aesthetic, ethical and religious perspective remains in the background.

Symbolic forms are an expression of the human mind, whose functions consequently embrace, as Cassirer and Scheler argue, language and reason as well as emotions, judgment, and consciousness of the lived body. The multitude of intentional acts is the anthropological basis for the variety of symbolic forms. They enable humans to entertain a broad spectrum of relations to the world, to fellow beings and to other creatures. Only if the whole range of intentions is actualized, reality in its complexity can be opened up. ${ }^{6}$ Science and technology are by no means the only legitimate symbolic forms; they have to be completed by those intentions that refer immediately to the living being in its subjectivity, to qualified perceptions and values, to aesthetic, existential and religious experiences. Under this perspective different cultures can learn from and complete each other. Yet ethics will differ, if, for example, nature, an embryo or a dying person is regarded in the light of empirical science instead of a religious perspective.

\section{The Process of Globalization and Modern Technology}

For centuries cultures could develop largely independently of each other. First in the $20^{\text {th }}$ century one of the symbolic forms gains an influence which changes the interplay of all symbolic forms within cultures and consequently the relation of cultures fundamentally: modern technology. The dynamic of modern society is based on a process of feed-back between scientific research, technological

5 Cf. E.Cassirer: Philosophie der symbolischen Formen, Darmstadt Bd.I: 19899 - Bd.II: 19878 - Bd.III: 19909.

6 M. Scheler, Wesen und Formen der Sympathie, Bonn: 1985, 112f. M. Nussbaum, Upheaval of Thought: The Intelligence of Emotions, Cambridge: 2001. 
inventions, and the promise of social progress. ${ }^{7}$ It is, so the article on 'technology' in the German Encyclopaedia of Philosophy, the goal of technology to enable new capabilities'. It nourishes the hope that it can better the quality of life of everybody everywhere in the world and solve nearly all problems. Consequently nearly every culture in Africa and Arabia, in Asia, America and Europe is longing for technology to achieve a more comfortable life, a higher social standard, medical care, clean water and electricity, and the possibility to communicate with everybody at any time around the world.

At first sight technology seems to be a neutral instrument, a mere tool that is compatible with every way of life and does not interfere into religious and ethical orientation. But even technology is, as Cassirer argues, a symbolic form which opens up reality under a special perspective and forms the wishes and needs, the emotions and the way of thinking. 'Technology', so the definition in the Encyclopaedia of Science and Religion, "understood as practical implementation of intelligence, is a matter of know-how expressing values." 8 Every technology reflects the goals and values of the innovator and of the social and historical context in which he lives and works. It changes daily life and in a process of feed-back the self-understanding of humans. It produces completely new wishes and hopes and undermines inevitably traditional forms of life. The more the power to control natural, social and even psychic processes increases, the more humans feel as creator of the conditions of life. The wish to shape the world in the light of human ideas goes from strength to strength. Fate and chance have to be eliminated. Driven by wishes and needs the development and distribution of technology accelerates in combination with a globalized economy. ${ }^{9}$ Man, so Cassirer "ist auf einen an sich

$7 \quad$ Cf. F. Bacon, Neues Organon der Wissenschaften, Darmstadt: 1990, 99 und 60. V. Hösle, Philosophie der ökologischen Krise, München: 1991.

F. Ferré, "Art, Technology," in Encyclopaedia of Science and Religion, New York: 2003, Band II, 868.

9 H. Jonas, Technik, Medizin und Ethik. Die Praxis des Prinzips Verantwortung, Frankfurt/M: 1987, 16; 20f; 24. 
grenzenlosen Weg des Schaffens verwiesen, der ihm kein schlechthin endgueltiges Ziel mehr verspricht." ${ }^{10}$

Modern technology undermines the boundary between cultures and promotes the tendency to a unified life-style. On the one hand the danger to lose cultural identity is growing; on the other hand the dynamic inaugurated by modern technology implies the opportunity to strengthen the autonomy and the responsibility of the individual, as Amartya Sen argues and to discover common goals and values. ${ }^{11}$ Humans have to reflect on their way of life consciously and to decide between alternatives. This process is the very basis of democracy. But science and technology in their combination with economy do not give any reasons for ethical values and the meaning of life. Only ethical values which transcend the different cultures and are shared by all humans enable to steer and to limit the dynamics of modern technology and economy.

\section{Ethics in the Horizon of Globalization}

Modern technology that spreads over the whole world consequently provokes ethical questions that affect all humans: The striving for a higher social standard in combination with the growing population leads to the exhaustion of nature and the climatic change; nuclear technology can destroy huge areas of land independent of national and cultural borders; biotechnology can manipulate the genetic code of plants, animals and humans and create clones, it can make use of embryonic stem cells and of the organs of dying persons. Though the reason why human life should be safeguarded against technical, medical and economic abuse is influenced by the cultural tradition, a common ethical orientation can be recognized. The intrinsic value of human life may be seen as divine gift, it may be deduced from the capability to ethical judgment as Kant argued, or it may be based on self-respect:

10 E. Cassirer, "Form und Technik," in Ders, Symbol, Technik, Sprache, Hamburg: 1985, 67.

11 A.Sen, Die Identitätsfalle. Warum es keinen Krieg der Kulturen gibt, München: 20072, insb.33-53. 
In any case humans have the duty to respect fellow humans, independent of culture, nation, religion, social function and gender. The idea of the dignity of humans that was articulated in 1948 by the United Nations Organization and that is the basis of human rights, was accepted as ethical orientation by many nations. For ethical argumentation it is irrelevant when and where this idea first arose, $^{12}$ and if it can also be found in non-European cultures. Essential for the foundation of ethical orientation is that humans agree that life has an intrinsic value. Though the way how the idea of dignity is practiced will vary with the cultural background, it eliminates an ethical relativism. As an idea it implies a distance to the historical situation and to traditions which have been handed down for generations. No tradition is true only because it is old. It has to be analyzed and corrected in the light of the idea of dignity.

Not by means of theoretical reflection, but due to the pressure of the circumstances another global dimension of ethics comes to the fore. The ecological crisis makes aware that human identity cannot sufficiently be defined by rational acts; as 'animal symbolicum' their identity is also based on the lived body. Yet, ecology that is bound to the scientific method cannot give reasons that mankind should survive. Only if the existence of humans is accepted as an ethical value that should be preserved, the duty to sustain the necessary conditions of life can be derived. And because the dignity of humans is an idea that is not bound to the empirical individual, it should be preserved in the present as well as in future. Also the generations to come should be able to survive and, beyond this, to live corresponding to the respect they owe to human dignity.

Biologically spoken all living beings are open systems. Life depends on the continuous exchange of matter and information with the surrounding. But the functioning of an organism cannot be explained by the accidental overlapping of incoherent events. It does not depend on the quantity of elements and their causal interaction, but on their structural and functional integration. An durchsetzbar?, Berlin: 20072 . 
organism has to be conceived as a whole, as an inseparable unity in the multitude of functions. Without any doubt the explanation of certain diseases may be based on cultural definitions. Yet the survival of an organism depends on some well-defined physiological functions, for example the temperature or the blood pressure. Also the minimum humans need for the biological survival depends only to a minor degree on cultural and personal habits, but on the physiological constitution of Homo sapiens. The temperature on this planet cannot be much higher or lower; a certain amount of oxygen is necessary; radiation causes severe illness, genetic mutations, or even death; and a minimum of food and water is necessary for the metabolism. ${ }^{13}$

Yet an organism cannot exist through itself. Biological survival is based on a fragile balance between the physiological needs and the order of the environment. Self-preservation depends on permanent self-transcendence to the environment. An organism is related essentially to the environment, in which it is embedded.

Yet the body of a living being cannot be conceived as empirical object that can be localized in space and time and described analytically by an external observer under the perspective of the third person. The lived body transcends itself in a twofold manner: by metabolism and by the expression of qualitative perceptions and intentional acts. The body is by no means a passive instrument for mentally conceived goals, as Descartes had supposed. It is felt from within qualitatively. Therefore no event appears as mere fact; it has a meaning for an organism which feels pain and pleasure, needs and desires, fulfilment and failure. The inner life is expressed bodily in actions, speech and gesture. Therefore the inner life can at least to a certain degree be observed by fellow humans and by other creatures. The physiological functions of the body that can be explained scientifically and the lived body as the expression of moods and intentions belong together. "Our bodies", so Whitehead, "lie beyond our individual existence. And yet they are

13 R. Spaemann, Grenzen. Zur ethischen Dimension des Handelns, Stuttgart: 2001, 142. 
part of it. [... ] Thus we arrive at this definition of our bodies: The human body is that region of the world which is the primary field of human expression." 14

Human identity is essentially related to fellow humans and to its surrounding, to culture and to nature. ${ }^{15}$ Identity can neither be conceived as invariable substance nor exclusively based on mental acts. It has to be defined, as Plato has argued in the 'Sophists', by its relation to otherness. This relation is by no means static. It has to be developed in an ongoing process of self-transcendence and of selfcentredness. Data are perceived, transformed, judged, and finally connected with former experiences. Thereafter the individual will express its point of view in speech and actions which transform its relations to the surrounding and change the starting point for further actions irreversibly. On the one hand an individual responds to challenges from the surrounding, on the other hand it transforms it by its own actions and creates new challenges. Slightly, but nonetheless inevitably, every individual changes the conditions of future life. To conceive human identity as an ongoing process implies that also its surrounding must be interpreted dynamically.

Yet, the great order of nature cannot be conceived as mere collection of separated entities that interact accidentally and mechanically. In contrast to lifeless objects living beings are adapted to a special environment that is constituted by streams of matter and the activities of a multitude of other species. Nature is by no means a 'Zeugzusammenhang' (Heidegger), an ensemble of objects that exist independently of each other and that can be arranged by human interests. The stability of an ecosystem depends on the correlation of the needs and life cycles of all entities. As open systems living beings have to make use of their environment. In accordance with the second law of thermodynamics they produce waste-products even without any

14 A. N. Whitehead, Modes of Thought, New York: 1968, 21f, 115.

15 Cf. R. Kather, Person. Die Begründung menschlicher Identität, Darmstadt: 2007. 
technical influence and transform the conditions of life steadily. In an ongoing process of separation and integration of information, matter, and energy the unity of an organism is created together with the "connexity of the world." 16 Nature can no longer be interpreted as mechanism, as a sort of clockwork, whose structure is governed by invariant laws. Nature is constituted by a spatial and temporal order that is maintained by the highly structured interplay of inorganic processes and innumerable species.

Also humans can only survive, because they are adapted physiologically to the present composition of the ecosphere. They can only by means of high technology survive in space or on the bottom of the sea. Humans are embedded bodily in nature which they transform irreversibly by the fulfilment of their vital needs. Yet even these fundamental actions are not mere reactions to needs, but the expression of cultural values and aims. They determine how biological needs as hunger, sexuality, and physical protection are satisfied. Everywhere in the world birth, marriage, and death are bound to symbolic rites. Humans can decide to concentrate on traditional methods of agriculture or develop genetically modified plants and animals. Although genetic variation is a natural process, genetic modification differs in at least one respect: Special properties of plants and animals are selected by humans and introduced into an ecosystem in high quantities in a very short scale of time. For other species is no time left to adapt to the new members of the community by a process of co-evolution. Therefore the correlation of species may be severely disarranged.

Humans can neither be regarded as biological organism, whose functions can be described by biology; nor can they be characterized as cultural beings that have a body which is without any meaning for the personal identity. Both aspects are intertwined: On the one hand humans are as living beings embedded in nature; it is the necessary condition of the possibility of biological survival and therefore for the development of culture as symbolic interpretation of nature. On the other hand humans are

16 A. N. Whitehead, Modes of Thought, New York: 1968, 165. 
already in their biological functions part of culture. Though the dynamic of nature and the dynamic of culture differ, they interfere mutually. As 'animal symbolicum' in the literal sense of the word humans participate in nature, - by their physiological needs and their cultural goals. Humans cannot leave the biosphere and make use of it like a technician who modifies an object due to his own projects. In Africa as well as in Asia, in America or in Europe humans are an integral part of the biosphere which they modify by their actions. This insight changes the starting point of ethical reflections fundamentally.

If humans appreciate their life and that of the members of their species, they must have a vital interest in preserving nature. ${ }^{17}$ Already ancient cultures have caused irreparable damages of nature: the clearing of the Apennines, of the Spanish peninsula, and of Croatia causes to this day the erosion of the soil and the expansion of the desert. ${ }^{18}$ But first since the second half of the $20^{\text {th }}$ century humans can destroy the whole planet in a few seconds. Even actions that are useful for daily life as refrigerators and cars have due to the huge number of users a global impact that extends over hundreds of generations. The manipulation of the genetic code will be transmitted to future generations; radio-activity will contaminate soil and water for thousands of years; and the clearing of the jungle in Brazil changes the climate worldwide.

Consequently the basis of ethics has shifted in a significant way: Socrates could argue that it is better to live ethically than to survive; and Jesus offered his life for salvation. For the individual the aim of life was not mere survival, but the realization of the 'differentia specifica', of those capabilities that humans do not share with animals. Ethical values should help to transcend the sphere of biological needs and vital interests. Also today it is highly

17 Cf. J. Grange, Nature. An Environmental Cosmology, New York: 1997. R. F. Nash, The Rights of Nature. A History of Environmental Ethics, Madison: 1989, 107.

18 Cf. J. Diamond, Kollaps. Warum Gesellschaften überleben oder untergehen, Frankfurt/M: 200533. 
respected, if an individual risks his life, because he or she resists injustice. But if human life in general represents an intrinsic value, nobody must risk the conditions of the survival of humanity. The highly structured order of the biosphere is one of these conditions. Therefore the relation of humans to nature cannot be interpreted as mere language game which varies from one culture to another, and ethics can no longer be restricted to inter-subjective relations; it has also to discuss the dynamic and the meaning of nature. Though values cannot be derived immediately from being, they do not only depend on rational consensus, cultural tradition, and the balancing of human interests. They have an existential meaning for humans and an ontological foundation in their constitution and in nature which transcend the difference of cultural interpretations.

Yet survival is only a necessary, not a sufficient condition for the realization of higher qualities of life and the realization of the whole span of human capabilities: the sensual and aesthetic aspects of life, a socially and ethically good life, and religious contemplation. ${ }^{19}$ Nevertheless the argument that survival is the basis for the realization of higher values does not imply the conclusion that the satisfaction of basic needs must not yet be orientated ethically. If we regard humans as unity of body and mind and as part of nature and culture, the argument that people first have to take care of their vital needs, and thereafter will gain the freedom to care for ecological problems, is anthropologically wrong. Already in respect to their biological needs humans are, as we have seen, part of culture; its goals and values help to choose and to judge the means used for the satisfaction of vital needs. Traditions and former experiences are often not sufficient for the orientation in a globalized and technically mediated context. If humans strive for survival, their actions must be locally as well as globally adapted to the dynamic of the whole ecosphere. This insight implies for almost every culture a new challenge, though each of them has its specific starting point. Only if the biosphere in its complexity and its intrinsic dynamic is preserved, natural 
resources can regenerate for a very long time. Nevertheless they are, due to the second law of thermodynamics, finite as every process in this world.

Beyond this it is not sufficient to reflect on the motives of a decision and on their instantaneous effects on contemporaries. Ethics, as Jonas argues, has explicitly to take into consideration the horizon of time; it has to deal with future effects as far as they are possible and can be anticipated. Modern ethics therefore bridges the gulf between a Kantian type of ethics that judges motives and the utilitarian type that deals with consequences. Human responsibility extends as far as the technological power of individuals, institutions, and nations.

Yet, another aspect of time has to be taken into account. It deals with the difference between a concept of time based on measurement that is fundamental for modern society, for economic strategies and political decisions, and the cyclical structure of biological and ecological processes. The permanent exchange of information, goods, and even persons depends on a unified scale of time. Time is a mere parameter, an external measure that is completely separated from its content. Therefore time appears to be homogenous, linear, and without any meaning. It seems, as if everything could be done at every moment and everywhere.

In contrast to the scientific concept of time that dominates daily life, physiological and ecological processes are determined by cycles that run through qualitatively different phases. After a certain span of time they return into nearly the same state. ${ }^{20}$ Though the velocity of the cycle can vary, the succession of phases cannot be exchanged or even turned around. In the same quantity of time qualitatively different aspects of the cycle are run through. Therefore it is impossible to do everything at any time. Not an open, linear succession of independent events, but a closed, circular dynamic is

20 K. Kümmerer, Rhythmen der Natur. Die Bedeutung von Eigenzeiten und Systemzeiten, in M. Held \& K. Geißler, ed., Von Rhythmen und Eigenzeiten, Stuttgart: 1995, 97-118. 
constitutive for the preservation and long lasting regeneration of living beings and ecosystems. If these processes are uncoupled, physical and psychic well-being decreases.

It is inevitable that the permanent acceleration of the modern way of life and the comparatively slow regeneration of natural resources and their mutual interdependence conflict with each other. Human actions which take into consideration only the quantitative aspect of time cause a severe disintegration of the different components of an ecosystem. The capacity to regenerate decreases and may finally lead to a complete breakdown. Responsibility for nature implies therefore the adaptation of cultural goals to biological rhythms, including those of the human body. ${ }^{21}$

Up to this point ethics remains utilitarian and anthropocentric. Only if nonhuman creatures and finally nature as a whole has an intrinsic value, humans are responsible for the whole range of beings and their interrelations for their own sake. Due to the process of evolution humans participate at least to a certain degree in the subjectivity of other creatures. As a unity of body and mind they take part in the community of life though they differ from all species due to the capability to reflect on motives and goals. The 'differentia specifica' is the foundation of ethics which implies duties against all living beings. If, as Schweitzer, Jonas, and the Swiss constitution argue, every living being strives for life and has therefore an intrinsic value, it has to be respected for its own sake, due to the dignity of creatures. ${ }^{22}$

21 J. Aschoff, Die innere Uhr des Menschen, in H. Gumin \& H. Meier (Hg.): Die Zeit. Dauer und Augenblick, München: 1989, 133-144.

Cf. H. Jonas, Philosophische Untersuchungen und metaphysische Vermutungen, Frankfurt/M: 1992, 17. P. Balzer, P. Rippe, and P. Schaber, Menschenwürde vs. Würde der Kreatur. Begriffsbestimmung, Gentechnik, Ethikkommissionen, Freiburg/ München, 19992. H. Baranzke, Würde der Kreatur? Die Idee der Würde im Horizont der Bioethik, Würzburg: 2002. 
Yet, all living beings are part of the web of life. Therefore they have also an instrumental value for fellow creatures and the whole ecosphere. In a slight modification of Kant's Categorical Imperative one can argue, that they are at the same time means for other creatures and end in themselves. This argument leads to another consequence of modern ethics: The relation to otherness is, as we have seen, constitutive for the identity of every living being; consequently the destruction of an entity and of the relations, by which it is tied to the world, implies also an injury against one's own self.

The insight that living beings have an intrinsic aim transforms the concept of nature and the relation of humans to nature as well as their self-understanding fundamentally. Though they are endowed with reason, humans are embedded in nature as a meaningful process. They are not, as Pascal, Heidegger and Sartre have supposed, thrown into a completely strange and senseless world which is moved by mechanical forces and open to exploitation.

Under these premises the amelioration of the conditions of human life cannot be based on the extinction of fellow creatures; the striving for a better quality of life implies the striving for their wellbeing. The multitude and variety of species is the basis for the abundance of life. Though humans have, at least on this planet, the highest form of consciousness, they depend in every moment of their life on the restless and highly organized activity of a variety of tiny and completely unimpressive organisms. „We find ourselves”, as Whitehead writes, "in a buzzing world amid a democracy of fellow creatures." 23 Under these premises ethics embraces the intrinsic value of the fellow creatures and their interrelations in the ecosphere. The whole range of being has a functional and an intrinsic value. ${ }^{24}$

23 A. N. Whitehead: Process and Reality. An Essay in Cosmology, ed. David R. Griffin and D. W. Sherburrne, London: 1978, 50.

24 Cf. B. Henning, The Ethics of Creativity. Beauty, Morality and Nature in a Processive Cosmos, Pittsburgh: 2005. 
From the empirical concept of being no 'ought' must be derived, as we know. But the concept of being changes fundamentally, if all living entities are at least to a minor degree endowed with subjectivity - as Darwin and most theological traditions argue. Being now is not a mere fact, but implies meaning, aim and value which are independent of human consent. The idea of dignity of creatures has an ontological foundation and gives, as the idea of human dignity, a fundamental ethical orientation, but it does not prescribe concrete actions. Therefore the question how human actions can respond to the inherent value of fellow creatures has to be discussed in every context anew. Within this ethical frame every culture has to develop its own strategies.

Obviously the rediscovery of the dynamic of nature during the last century has far-reaching consequences for the concept of human identity and for ethics. Humans are, as Goethe has argued, spectators of and participants in nature at the same time. ${ }^{25}$ The concern for one's own wellbeing implies the concern for nature. Self-determination and freedom imply the capability to preserve the relations to otherness. ${ }^{26}$ The protection of nature is therefore one of the guide values of the 21th century that bridges the gulf between different cultures, as Jonas argues: „Die gesamte Biosphäre beansprucht gegenüber den Eingriffen des Menschen ihren Anteil an der Achtung, die allem gebührt, das seinen Zweck in sich trägt, das heißt allem Lebendigen. " 27 in 14 Bänden, (Hg. E.Trunz), Bd. 13, München: 19829 , 45-47. 